Rabaska

Revue d'ethnologie de l'Amérique française

\title{
Initiatives en français du Middle West des États-Unis (Université du Dakota du Nord)
}

\section{Virgil Benoit}

Volume 12, 2014

URI : https://id.erudit.org/iderudit/1026839ar

DOI : https://doi.org/10.7202/1026839ar

Aller au sommaire du numéro

Éditeur(s)

Société québécoise d'ethnologie

ISSN

1703-7433 (imprimé)

1916-7350 (numérique)

Découvrir la revue

Citer ce document

Benoit, V. (2014). Initiatives en français du Middle West des États-Unis

(Université du Dakota du Nord). Rabaska, 12, 359-360.

https://doi.org/10.7202/1026839ar d'utilisation que vous pouvez consulter en ligne. 
francophones honore la mémoire de Vivienne-R. Côté, une Franco-Américaine du Rhode-Island qui consacra sa carrière d'enseignante à la francophonie. En 2014 $\mathrm{M}^{\mathrm{me}}$ Choquette fut aussi élue à la présidence de l'American Council for Québec Studies (AcQs), la principale organisation des québécistes aux États-Unis. Au cours de l'année scolaire passée, elle a donné des communications aux États-Unis, au Canada et en Autriche, et elle a écrit plusieurs articles sur les francophones en Amérique du Nord. Elle participe également aux initiatives franco-américaines du Centre de la francophonie des Amériques à Québec.

LesLie Choquette

\section{Initiatives en français du Middle West des États-Unis}

320, Merrifield Hall

Box 8198

Université du Dakota du Nord

Téléphone : (701) 777-4659

Grand Forks, North Dakota

ND 58202, États-Unis

Télécopieur : (701) 777-3814

Courriel: virgil.benoit@und.edu

Toile: http://und.edu/orgs/initiatives-in-french-midwest

Depuis le premier rapport paru dans cette revue (Rabaska, vol. 11), les activités liées à la francophonie dans le Middle West des États-Unis ont progressé de la manière suivante.

Initiatives indépendantes des IFMidwest

- On a fondé en 2014 The French-American Heritage Foundation of Minnesota, une société à but non lucratif qui s'est donné comme mission « de promouvoir et de développer les cultures d'expression française par l'éducation et au moyen d'événements ouverts au public. » (Toile : http://fahfminn.org/about-french-american-heritage-foundation).

- De même, l'association Les Survivants : Great Lakes French Canadians - Minnesota s'est donné pour mission de promouvoir la culture canadienne-française pour faire renaître la fierté de ses racines par l'éducation et des activités sociales, et de favoriser un rapprochement entre l'État du Minnesota et le Québec ainsi qu'avec le Canada francophone. Toile : www.lessurvivants.org.

\section{Les activités auxquelles participent les IFMidwest}

- « La collecte d'information (2014-2015) ». Ce projet du Dakota du Nord implique un total de cinq communautés d'origine canadienne-française et une communauté de forte influence métisse : Wild Rice, Rolette, Olga, Oakwood, et Belcourt. On se propose de sonder les mémoires et les pratiques provenant du Canada français depuis leur origine à nos jours. Il s'effectuera en trois étapes : 1. questionnaire ; 2. entrevues ; 3. captations vidéo. On souhaite en tirer une série de présentations publiques à travers l'État. 
- «L'histoire de la présence canadienne-française dans l'État du Dakota du Nord » sous la direction de Jean Lamarre en collaboration avec Yves Frenette et Virgil Benoit. Le livre mettra au jour le rôle pionnier des Québécois dans l'ancien territoire qui est devenu le Dakota du Nord, l'apport des immigrants québécois, des particularités de la vie métisse au Dakota du Nord, et la vitalité actuelle du patrimoine québécois au Dakota du Nord.

- «Charles Morin, Charpentier itinérant » [titre provisoire]. Ce livre présentera les souvenirs ou mieux la vie quotidienne liée au travail d'un charpentier québécois des années 1869-1883 avant qu'il décide de s'établir à Argyle au Minnesota. Yves Frenette, France Martineau et Virgil Benoit en préparent l'édition critique (2015).

- «Le festival canadien-français et michif » dévoilera en 2014 sa $33^{e}$ édition en invitant sur scène le violoneux franco-manitobain Michael Audette et son orchestre ainsi que la troupe franco-manitobaine de danse Ça claque les 23 et 24 août 2014 au parc du traité Old Crossing à Huot (comté de Louisville, Minnesota).

- Le dernier numéro du magazine IFMidwest 2014 contient trois articles d'approche ethnographique : 1 . Le premier texte d'une série de trois sur la pratique de la musique michif par un trio du nord-ouest de l'État du Minnesota ; 2. "Laurent Brunelle, photographer of the rare » et 3. de Ted Stone, «Bottineau : from history to story». - La communauté du comté de Louisville, Minnesota entreprend une étude de faisabilité au sujet de la construction d'un centre culturel (2014-2015).

- Le directeur des IFMidwest participera au colloque sur Marius Barbeau (2014).

VIRGIL BENOIT

Centre de folklore acadien et créole

Center for Acadian and Creole Folklore

University of Louisiana at Lafayette

Lafayette, LA 70504
Téléphone : (337) 4826811

Télécopieur : (337) 4825446

Courriel: ancelet@louisiana.edu Toile : http://languages.louisiana.edu French/centeracadian.html

\section{Mandat et collections}

Le centre (CFAC) continue à mettre ses collections historiques et contemporaines à la disposition du public (chercheurs, musiciens, cinéastes, enseignants, etc.), et à organiser des festivals et des spectacles spéciaux, des émissions de télévision et de radio. Il continue à dispenser des cours et des ateliers au sein des programmes universitaires, surtout en Études francophones, Histoire, Musique, et Anthropologie culturelle. Le CFAC continue à produire des documents - livres et articles, disques et vidéos - qui diffusent ces créations et ces réinterprétations auprès de la communauté et des étudiants. Il participe toujours à la production des Festivals acadiens et créoles, soit la deuxième fin de semaine d'octobre chaque année.

\section{Projets}

Cette année, les Festivals acadiens et créoles fêtent leur $40^{\mathrm{e}}$ anniversaire, ainsi que 